\title{
AN INTEGRATED APPROACH FOR THE REPRESENTATION OF CONCRETE GRAVITY BASED FOUNDATIONS FOR OFFSHORE WIND TURBINES
}

\author{
Maxime PHILIPPE* \\ INNOSEA \\ Nantes, 44321 \\ France \\ Email: maxime.philippe@innosea.fr
}

\section{Panagiotis KOTRONIS}

LUNAM Université, Ecole Centrale de Nantes Université de Nantes, CNRS

Institut de Recherche en Génie Civil et Mécanique (GeM) 1 rue de la Noë, F-44321 Nantes, France

Email: Panagiotis.Kotronis@ec-nantes.fr

\author{
Bruno BORGARINO \\ INNOSEA \\ Nantes, 44321 \\ France \\ Email: bruno.borgarino@innosea.fr \\ Guillaume DUCROZET \\ LHEEA Lab. (ECN-CNRS) \\ École Centrale Nantes, LUNAM Université \\ Nantes, 44321 \\ France \\ Email: guillaume.ducrozet@ec-nantes.fr
}

\begin{abstract}
This paper describes a novel approach to efficiently simulate the structural dynamics of a concrete Gravity Based Foundation $(G B F)$. In this time-domain analysis, the GBF is subjected to loads applied by the turbine, wave loads and the influence of the soil structure interaction is taken into account. Wind turbine loads are computed using the aeroelastic software FAST and expressed at the connection point between the turbine and the GBF. Wave loads on the GBF are computed using a potential, nonlinear wave model. Nonlinear soil-structure interaction is modelled with the use of a macro-element specifically developed for shallow foundations. Finally, the structure itself is modelled using an Euler-Bernoulli multifiber beam, which allows representing the reinforced concrete sections.

It is shown that the numerical model is able to efficiently simulate the behaviour of a GBF foundation under nonlinear irregular wave forces and loads transmitted by the turbine. It reproduces nonlinear phenomena such as a decrease in material stiffness due to damage and permanent strains but also the GBF displacements considering soil structure interaction.
\end{abstract}

\section{INTRODUCTION}

As the offshore wind industry expands in Europe, a wide variety of foundation designs are considered. Gravity based foundations $(\mathrm{GBF})$ have the advantage of being competitive for shallow waters, and have a limited environmental impact during installation.

The design and certification processes for offshore wind turbine foundations require a high number of simulations to be performed (it can easily exceed 3000). In the case of steel foundations made of slender members such as monopiles, jackets or tripods, simulations by the Finite Element Method (FEM) can quickly be carried on, using beam elements. The wave loadings are computed by the Morison method. On the other hand, the engineering of concrete GBF has several challenges:

- The substructure itself is not slender, thus the Morison method is not appropriate to calculate wave loads. Plus, such substructures are installed in limited water depths, at which the linear wave theory is not valid for large wavelengths.

- The use of solid, 3D finite elements to simulate reinforced concrete sections leads to high computational times.

- The use of solid, 3D finite elements to simulate soil structure

\footnotetext{
*Address all correspondence to this author.
} 
interaction can again lead to high computational times.

In the field of earthquake engineering, fast and accurate numerical tools have been recently developed, able to simulate the nonlinear behaviour of complex structures. Multifiber beam elements [1], [2], following the Euler-Bernoulli or the Timoshenko kinematic hypothesis, allow a simpler representation of the structure with a limited number of elements. Each section is made of different materials and each material follows a specific nonlinear constitutive law. This type of modelling strategy has been used to model the dynamic behaviour of reinforced concrete buildings submitted to earthquake loadings (see for example the 5-floor building simulated in [1], with only 24 beams and 37 fibers in each section). More recently, a 3-pier concrete viaduct has been modelled using 21 Timoshenko multifiber beam elements. Each section is made of 40 concrete fibers and 8 steel fibers [3]. For the dynamic simulations, concentrated (lumped) masses are introduced at the nodes.

When it comes to concrete structures under cyclic or earthquake loadings, suitable constitutive laws have to be considered. In the finite element calculations presented in [1] or in [3], the concrete and steel constitutive laws are chosen following [4] and [5] respectively.

Concrete substructures are stiff, so most of the loads are transferred to the soil. Consequently soil-structure interactions must play a role in the foundations dynamics, and have to be taken into account in the analysis. The classical engineering approach to model these interactions is to use linear springs but their stiffness is difficult to calibrate a priori. On the other hand, a 3D finite element modelling to consider soil-structure interaction is time consuming and cannot be used for a large set of dynamic load cases. [6] developed a 2-nodes macro-element capable of representing the nonlinear soil structure interaction for a circular, superficial foundation. This macro-element is able to represent the following phenomena: elasticity, plasticity of the soil and uplift of the foundation. Some of the macro-element parameters can be calibrated using the soil properties and the foundation geometry. The other parameters do not vary much according to literature. It can be coupled with a multifiber finite element modelling for the upper structure, as shown in [3].

This paper aims at evaluating the applicability of these tools, to simulate the dynamic behaviour of a concrete GBF, with external forcing from the wind turbine, and wave loads computed with a nonlinear irregular wave model. First, a comparison is made for the case of a cantilevered substructure, with linear and nonlinear constitutive laws for the reinforced concrete. The objective is to demonstrate the ability of the model to capture nonlinear structural phenomena. Then, the nonlinear foundation macro-element is added to represent soil-structure interactions and to evaluate their effect on the GBF dynamics.

\section{MODEL PROPERTIES Gravity based foundation properties}

A general GBF design is needed to evaluate the applicability of the simulation tools. A simplified GBF design has been proposed, inspired by GBF substructures at the Thornton bank offshore wind farm [7]. This substructure is by no mean a realistic, applicable design. The simplified GBF model is $45 \mathrm{~m}$-high and is situated in a water depth of $30 \mathrm{~m}$. The foundation diameter is $20 \mathrm{~m}$. The substructure is made of reinforced concrete and is ballasted (fully filled) with sand. Figure 1 shows the geometry of the GBF, and its main properties are summarized in Table 1.

\begin{tabular}{lr}
\hline Base diameter & $20 \mathrm{~m}$ \\
Diameter at connection with turbine & $6.5 \mathrm{~m}$ \\
Foundation height & $45 \mathrm{~m}$ \\
Foundation draft & $30 \mathrm{~m}$ \\
Wall thickness & $0.5 \mathrm{~m}$ \\
Base height & $1.9 \mathrm{~m}$ \\
Number of steel bars in a section & 216 \\
Steel bars diameter & $4 \mathrm{~cm}$ \\
Concrete mass & $2653 \mathrm{t}$ \\
Steel mass & $327 \mathrm{t}$ \\
Ballast mass & $5445 \mathrm{t}$ \\
\hline
\end{tabular}

TABLE 1: Main properties of the GBF

\section{Wind turbine properties}

The wind turbine used in this study is the reference turbine NREL 5MW [8]. The hub-height is $95 \mathrm{~m}$ and the tower height is $76.6 \mathrm{~m}$. This tower is the same as in the floating wind-turbine version of the NREL 5MW [9]. The connection between the substructure and the tower base occurs 15m above MSL (Mean Sea Level), at the top of the substructure.

\section{Environmental conditions}

The offshore wind turbine is subjected to turbulent wind and irregular waves loading. Wind and waves are aligned and propagate from the negative $x$-direction. Significant wave height of the considered sea state is $3 \mathrm{~m}$, and its peak period is $8 \mathrm{~s}$. The mean wind speed is $11.4 \mathrm{~m} . \mathrm{s}^{-1}$. The $600 \mathrm{~s}$ time series of the irregular, 3D wind speed is based on a standard IEC Kaimal [10] turbulence model. Figure 2 shows the time series of the main component of the wind speed, in the $x$-direction. Wave elevation at the GBF location is represented on Figure 3. 


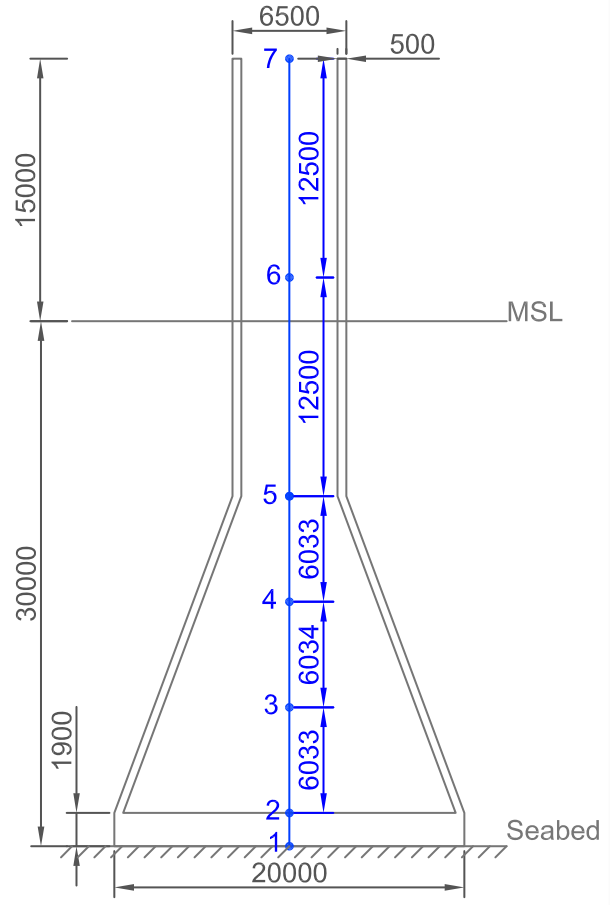

FIGURE 1: GBF Geometry. Measures are in mm. Blue dots represent the nodes of the multifiber finite element model; blue lines represent the finite elements. See Section "Structural modelling"

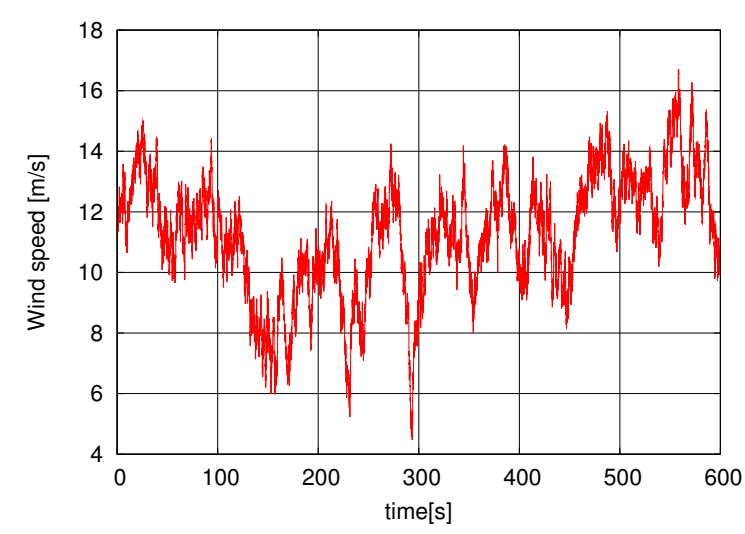

FIGURE 2: Main component of the 3D turbulent wind field at hub-height

\section{METHODOLOGY Overview}

The principle of the methodology presented in this paper is to integrate all relevant phenomena (aerodynamics, hydrodynamics, structural engineering, geotechnics) within the same simulation. Such a methodology leads to a more accurate combination of loads, thus reducing the sources of uncertainties.

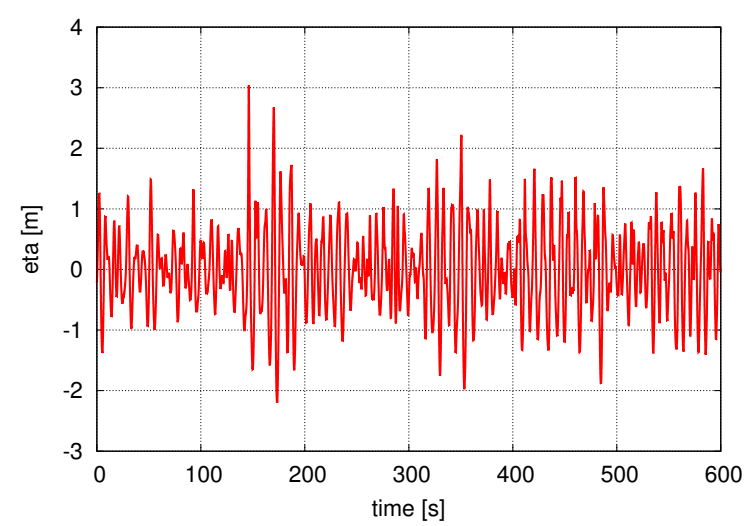

FIGURE 3: Wave elevation at GBF location

A combination of numerical tools has been used in this study:

- FAST design code from NREL has been used to compute the wind turbine dynamics.

- Hydrodynamic tools from LHEEA Lab. Ecole Centrale Nantes (ECN) have been used to compute hydrodynamic loads on the GBF. In-house nonlinear HOS incident wave model is used to compute wave kinematics. In-house diffraction/radiation code Aquaplus is used to compute linear diffraction loads.

- Structural dynamics of the sub-structure is modelled with a nonlinear multifiber beam model from GeM Lab. Ecole Centrale Nantes. Soil-structure interaction is also computed with an in-house model from GeM Lab.

Numerical codes are described in further details in the following sections. The innovation of this study is the combination of these codes for offshore wind turbine applications.

Wind turbine loads and wave loads are computed in a first step, then applied to the substructure. Wind loads are applied at the tower-substructure connection. Wave loads are distributed over the nodes of finite element model of the substructure. In this paper no couplings between the wind and wave loads and the substructure are considered. The motions of the substructure are supposed small enough to consider it fixed. As a consequence:

- The wind turbine tower behaves as a cantilevered beam and the wind loads can be computed regardless the substructure;

- No radiation hydrodynamic forces are applied to the substructure. The only wave loads are the Froude-Krylov excitation force and the diffraction force.

Several studies revealed that for flexible steel substructures such as monopiles, jackets or tripods the coupling between environmental loads and structural dynamics must be considered [11-13]. To our knowledge, no results are available in the literature to determine if such coupling is mandatory for GBF. If 
necessary, coupling between the GBF and the turbine can be implemented in a future work, by using one of the following methods used for steel substructures:

- Sequential coupling [12], based on a linear condensation of the substructure finite element model. This method is easy to implement, but nonlinear structural and soil dynamics cannot be considered in the analysis.

- Full coupling [13], based on the integration of the wind turbine representation in the finite element model as a macroelement. This method is more complex to manage, but is suitable for nonlinear calculations leading to a more accurate modelling of the system dynamics.

\section{Hydrodynamic modelling}

GBF are massive structures. Wave diffraction forces are significant and must be taken into account in the hydrodynamic calculations. Linear diffraction analysis supposes the linear Airy wave theory, which is only valid for small wave steepness and relatively deep water.

Henderson et al. $[14,15]$ studied the applicability of the hydrodynamic theory for the calculation of hydrodynamic loads on wind turbine substructures, in particular GBF. They concluded that it is necessary to evaluate the added mass coefficient of the support structure, and then to calculate the hydrodynamic loads based on the Froude-Krylov (pressure integration) method, using the added mass coefficient previously calculated in the diffraction analysis. The pressure integration method allows the use of a nonlinear wave theory.

Following these recommendations, a pressure integration method is used and combined with a nonlinear irregular wave theory to compute the Froude-Krylov loads. Diffraction loads are calculated following the linear potential theory.

The nonlinear wave model adopted is the High Order Spectral (HOS) wavemodel, developed at LHEEA Lab. The HOS method was initially proposed by West et al. [16] and Dommermuth and Yue [17]. The development of this method at LHEEA Lab. lead to a numerical wave tank (including wave generation, absorption, wall reflexions) [18] and an oceanic wave model [19], which can be coupled to sea-keeping models. The methodology for coupling the linear potential sea-keeping model and the HOS model [20] has been used in the present study.

Froude-Krylov loads are computed by integrating the dynamic pressure, calculated by the HOS model, on the instantaneous wetted surface. Diffraction loads are calculated using a combination of the linear potential method and the wave elevation calculated with the HOS model (see eg. Equation 3). Hydrostatic loads are computed as a mean buoyancy force applied on the nodes. One limit of the present methodology is that it does not take into account breaking wave loads.

Hydrodynamic loads are computed by the Boundary Element Method. Velocity potential, hydrodynamic pressure and the resulting forces are expressed at the center of each panel of a surface mesh of the substructure (see figure 6). These distributed forces have to be expressed at the nodes of the finite element model. For the Froude-Krylov force and the diffraction force, the following method is applied:

- Compute the hydrodynamic force at each panel;

- For each node $i$ of the finite element mesh, select the $N_{i}$ panels of the BEM (Boundary Element Method) mesh whose centers $z_{k}$ satisfy:

$$
\left(z_{i-1}-z_{i}\right) / 2<z_{k} \leq\left(z_{i}-z_{i+1}\right) / 2
$$

- Sum the contributions of the $N_{i}$ panels at each node $i$ :

$$
F_{i}=\sum_{k=1}^{N_{i}} F_{k}
$$

The wave loads are computed in the time domain, for each node $i$ and degree of freedom $q$, using the following equation:

$$
F_{\text {exi }}^{q}(t)=\underbrace{\sum_{k=1}^{N_{i}} p_{\text {dyn }} n_{k}^{q} S_{k}}_{\text {Froude-Krylov }}+\underbrace{\int_{-\infty}^{+\infty} K_{\text {difi }}^{q}(t-\tau) \eta(t) d \tau}_{\text {diffraction }}
$$

$p_{d y n}$ is the dynamic pressure due to the incident wave field, and $\eta$ is the surface elevation at the substructure center. $p_{d y n}$ and $\eta$ are calculated by the nonlinear HOS wave model. $n_{i}$ is the $i$-th component of the generalized normal vector of the panel $k, S_{k}$ is the surface of this panel. $K_{\text {difi }}^{q}$ is the diffraction impulse response. This response is obtained based on RAOs (Response Amplitude Operator) from the linear, frequency-domain hydrodynamic software Aquaplus [21], using equation 4:

$$
K_{d i f i}^{q}(t)=\frac{1}{2 \pi} \int_{-\infty}^{+\infty} f_{d i f i}^{q}(\omega) e^{\mathbf{i} \omega t} d \omega
$$

In Equation 4, $f_{\text {dif } i}^{q}$ is the RAO of the diffraction force at node $i$, computed from Aquaplus results on each panel using Equation 2. Figure 4 shows these values computed at nodes 2 to 5 . It can be seen that forces are highest at node 5 , because it is loaded on a large vertical span (from the free surface to the midpoint between nodes 4 and 5, see Figure 1). Nodes 3 and 4 come second because the substructure is larger at their level, thus diffraction loads are more important. Node 4 is the less loaded, probably because it is situated at mid-depth, where the substructure is only moderately large.

Figure 5 shows the final time domain results for the FroudeKrylov and the diffraction forces in the surge direction. 


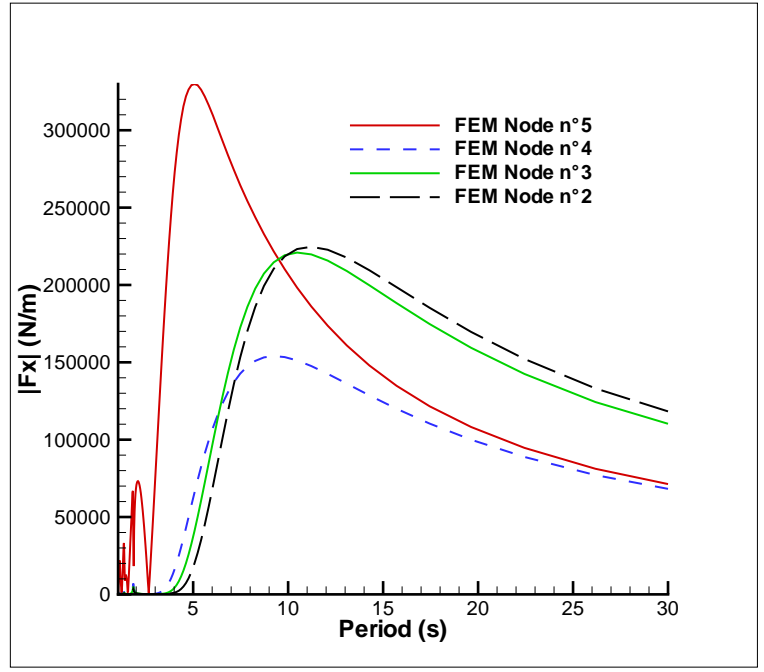

FIGURE 4: Diffraction force RAOs in surge, computed at FEM nodes (see Figure 1)

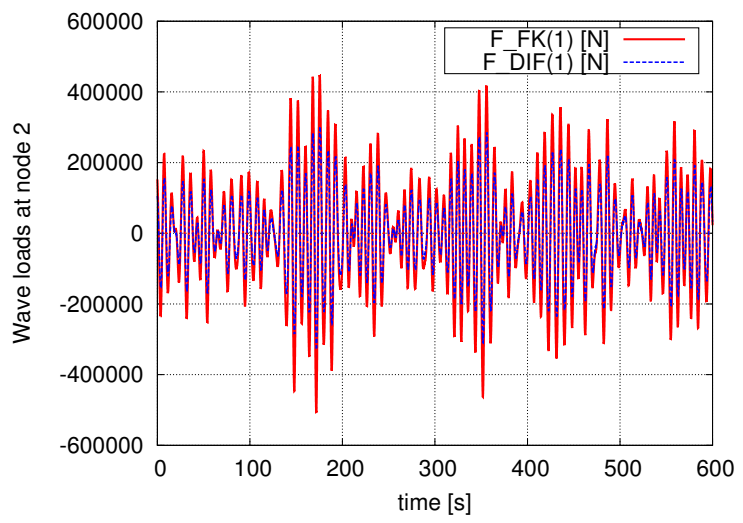

FIGURE 5: Wave loads at node 2 in the surge direction. Red, solid line: Froude-Krylov excitation force. Blue, dotted line: diffraction force.

\section{Structural modelling}

A finite element model using multifiber beams and concentrated masses is used to reproduce the nonlinear structural response of the GBF. The structure is discretised using 6 Bernoulli multifiber beams represented on Figure 1. 120 concrete fibers and 216 steel fibers are used in each section. Steel fibers represent the reinforcement bars at their actual position (regularly positioned in 2 concentric circles). Hydrodynamic loads and wind loads are computed independently and applied at the nodes. The weight of concrete, steel and ballast are also applied on the nodes. Calculations are made with FEDEASLab, a finite element matlab MATLAB toolbox [22].

The concrete constitutive model is based on damage me-

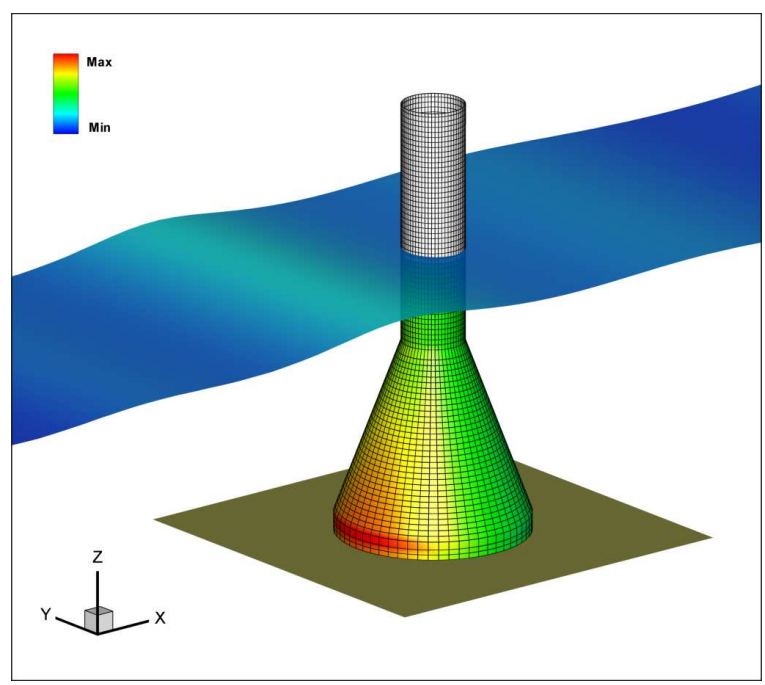

FIGURE 6: Froude-Krylov loads on GBF

chanics and is able to reproduce the nonlinear behaviour of the material for cyclic or dynamic loadings [4]. The plasticity model adopted for steel is a modified version of the classical Menegotto-Pinto model [5]. Material data for concrete and steel are listed in table 2 .

\begin{tabular}{cccc}
\hline \multicolumn{2}{c}{ Concrete parameters } & \multicolumn{2}{c}{ Steel parameters } \\
\hline$E$ & $20 \mathrm{GPa}$ & $E$ & $200 \mathrm{GPa}$ \\
$n u$ & 0.2 & $f_{y}$ & $460 \mathrm{MPa}$ \\
$Y_{01}$ & $380 \mathrm{~Pa}$ & $f_{s u}$ & $710 \mathrm{MPa}$ \\
$Y_{02}$ & $0.9 \mathrm{GPa}$ & $\varepsilon_{s h}$ & 0.0023 \\
$A_{1}$ & $6.00 \mathrm{E}-03$ & $\varepsilon_{s u}$ & 0.11 \\
$A_{2}$ & $5.00 \mathrm{E}-06$ & & \\
$B_{1}$ & 1.0 & & \\
$B_{2}$ & 1.6 & & \\
$\beta_{1}$ & $1 \mathrm{MPa}$ & & \\
$\beta_{2}$ & $-40 \mathrm{MPa}$ & & \\
$\sigma_{f}$ & $3.5 \mathrm{MPa}$ & & \\
\hline
\end{tabular}

TABLE 2: Material data for concrete and steel

$E$ is the Young modulus, $v$ is the Poisson ratio. $Y_{i}$ are the associated variables to the damage variable $(i=1$ for tension or 2 for compression) and $Y_{0 i}$ are the initial elastic thresholds. $A_{i}, B_{i}$ and $\beta_{i}$ are material constants. $\sigma_{f}$ is the stress for crack closure. $f_{y}$ and $\varepsilon_{s h}$ are the steel stress and strain at yielding and $f_{s u}$ and 
$\varepsilon_{s u}$ at rupture.

\section{Soil-structure interaction modelling}

A macro-element model is introduced at the base of the finite element model to take into account soil structure interaction. The macro-element is able to simulate the $3 \mathrm{D}$ behaviour of a rigid shallow foundation, submitted to cyclic loadings. The general formulation of the macro-element is detailed in [6] for the plasticity model, [23] for the uplift mechanism, [24] for the coupling of the two mechanics and [25] for the dynamic behaviour.

In the following, a class B soil according to the Eurocode 8 classification is considered at the base of the GBF. The adopted macro-element parameters are detailed in [3], see table 3. As mentioned before, the aim of the article is to show the ability of the macro-element to model the soil structure interaction for a GBF following an integrated approach. For a more precise study, the macro-element parameters have to be identified for a marine soil.

\begin{tabular}{|c|c|c|c|}
\hline soil & Stiffness & $\begin{array}{c}\text { Ultimate } \\
\text { bearing stress }\end{array}$ & $\begin{array}{c}\text { Plastic } \\
\text { parameter }\end{array}$ \\
\hline class B & $\begin{array}{c}K_{\theta \theta}=1299456.1 \mathrm{MNm} / \mathrm{rad} \\
K_{z z}=14715.87 \mathrm{MN} / \mathrm{m} \\
K_{h h}=23676.74 \mathrm{MN} / \mathrm{m}\end{array}$ & $q_{\max }=2.3 \mathrm{Mpa}$ & $\begin{aligned} \mathrm{a} & =0.32 \\
\mathrm{~b} & =0.37 \\
\mathrm{c} & =0.25 \\
\mathrm{~d} & =0.55 \\
\mathrm{e} & =0.8 \\
\mathrm{f} & =0.8\end{aligned}$ \\
\hline
\end{tabular}

TABLE 3: Macro-element parameters

\section{Wind turbine modelling}

In order to accurately assess the effect of wind loads on the structure, the aeroelastic software FAST [26] is used. FAST has the capability to fully model the dynamics of a wind turbine, including elasticity, aerodynamics and control in the time domain. As a consequence, the effects of cyclic loadings due to turbulent wind and of aerodynamic damping can be modelled, which removes possible sources of uncertainties and over-conservatism. Loads computed at the bottom of the turbine tower using FAST are then applied in the finite element model of the GBF substructure. Figure 7 shows the wind turbines loads, computed with FAST, and applied at the top of the substructure in the $x$ direction. The NREL $5 \mathrm{MW}$ wind turbine is controlled by a pitch controller. A mean wind speed of $11.4 \mathrm{~m} / \mathrm{s}$ has been chosen. This case is critical as the rotor thrust is maximal for this wind speed [8].

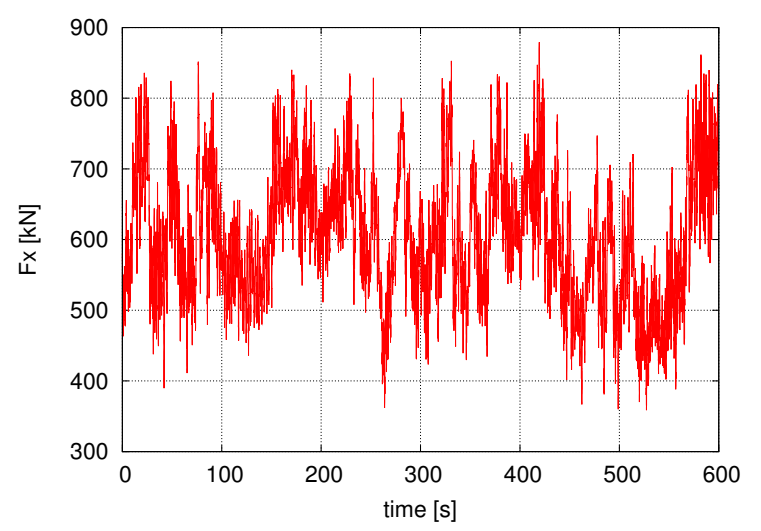

FIGURE 7: Wind turbine loads applied at foundation top in $x$ direction

\section{RESULTS \\ Effect of nonlinear constitutive laws for steel and con- crete}

In this section the results of two different finite element calculations are compared, considering linear and nonlinear constitutive laws for steel and concrete of the reinforced concrete structure. Soil structure interaction is not taken into account as the GBF is supposed fixed at its base. The aim is not to evaluate the design of the foundation, which is not realistic, but to evaluate the applicability of the proposed integrated methodology to reproduce nonlinear phenomena such as decrease in the structural stiffness due to damage and permanent strains.

Top horizontal displacements: Figure 8 shows the GBF top horizontal displacements considering a linear $8 \mathrm{a}$ and a nonlinear structural modelling $8 \mathrm{~b}$. One can observe that the mean deflection is found more important for the nonlinear structure. In other words, for this level of loadings and without considering soil structure interaction structural stiffness has decreased.

Concrete axial stresses: This decrease of the structural stiffness implies not also an increase of the GBF top displacements but also a decrease of the applied concrete stresses in the damaged sections. Figure 9 shows the axial concrete stresses in a section at the level of node 5 ; figure 8 a for linear constitutive laws, and figure $8 \mathrm{~b}$ for nonlinear constitutive laws. We can observe a decrease in axial concrete stresses in the non linear simulation. The section is damaged, cracking appears. Load is transmitted to the steel reinforcement bars that should be able to deal with more important axial stresses. 


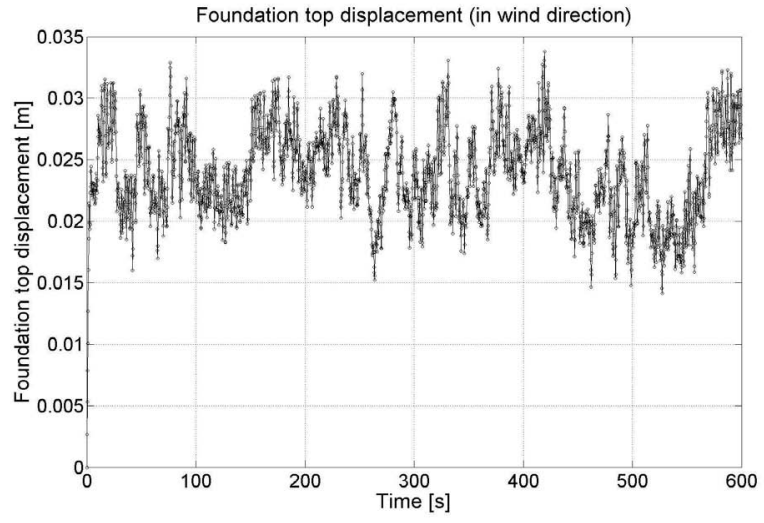

(a) linear

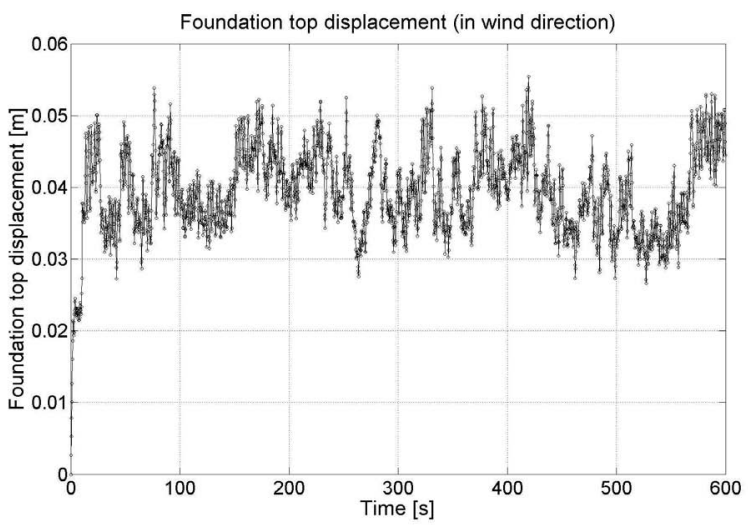

(b) nonlinear

FIGURE 8: Comparison of the GBF top horizontal displacements for the linear (fig. 8a) and the nonlinear (fig. 8b) structural analysis

Reinforcement axial stresses: One can observe in Table 4 that stresses in reinforcement bars actually increase when calculated using the non linear structural model. Nevertheless steel remains in the elastic domain. Figure 10 shows the axial stresses in a steel bar in a damaged section at the level of node 5, calculated with the non linear structural model.

Moment at the base: Even if nonlinear phenomena appear on the top of the substructure, it does not seem to have significant influence on the way forces are transmitted on the foundation. This is probably due to the fact that nonlinearities are limited (reinforcement remains elastic).

The power spectral density of the stochastic time series of the moment is shown in Figure 11. Such representation allows a first identification of the phenomena which influence the response. The main peak at $0.12 \mathrm{~Hz}$ corresponds to wave loads (the peak period being $8 \mathrm{~s}$ ). Power at lower frequencies are due to wind loads. For this loading case, waves slightly dominate the

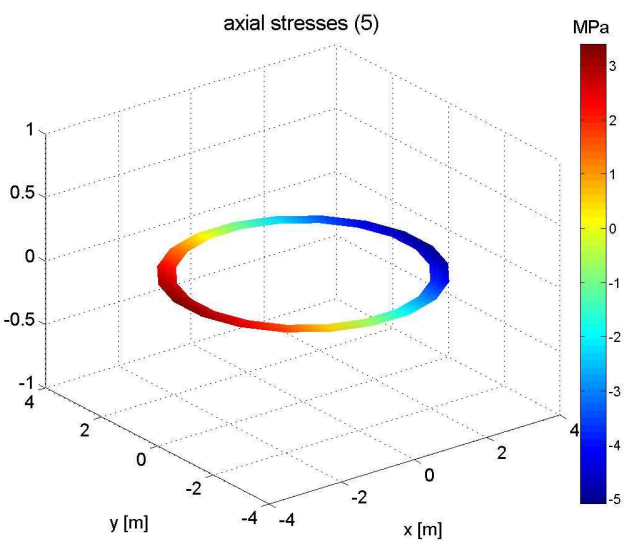

(a) linear

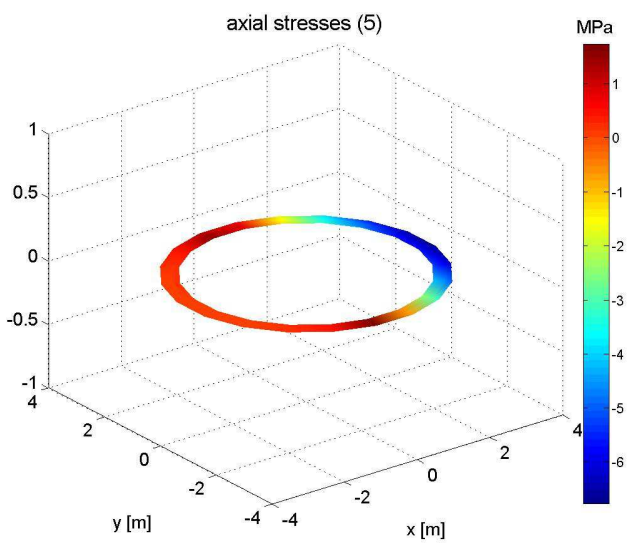

(b) nonlinear

FIGURE 9: Comparison of concrete axial stresses in a section at the level of node 5 for the linear (fig. 8a) and the nonlinear (fig. $8 b)$ structural analysis

\begin{tabular}{llccc}
\hline & & Linear & nonlinear & Diff. [\%] \\
\hline Top displacements [m] & mean & $2.38 \mathrm{E}-02$ & $3.93 \mathrm{E}-02$ & $65 \%$ \\
& $\max$ & $3.38 \mathrm{E}-02$ & $5.54 \mathrm{E}-02$ & $64 \%$ \\
& std & $3.70 \mathrm{E}-03$ & $5.90 \mathrm{E}-03$ & $59 \%$ \\
\hline Overturning moment (node 1) [kN.m] & mean & $7.56 \mathrm{E}+04$ & $7.56 \mathrm{E}+04$ & $0 \%$ \\
& max & $1.30 \mathrm{E}+05$ & $1.30 \mathrm{E}+05$ & $0 \%$ \\
& std & $1.61 \mathrm{E}+04$ & $1.61 \mathrm{E}+04$ & $0 \%$ \\
\hline Stresses in a steel bar (elem 5) [MPa] & mean & $2.54 \mathrm{E}+01$ & $7.33 \mathrm{E}+01$ & $188 \%$ \\
& max & $3.91 \mathrm{E}+01$ & $1.06 \mathrm{E}+02$ & $172 \%$ \\
& std & $5.15 \mathrm{E}+00$ & $1.27 \mathrm{E}+01$ & $147 \%$ \\
\hline
\end{tabular}

TABLE 4: Comparison of statistical results for the linear and the nonlinear structural analysis 


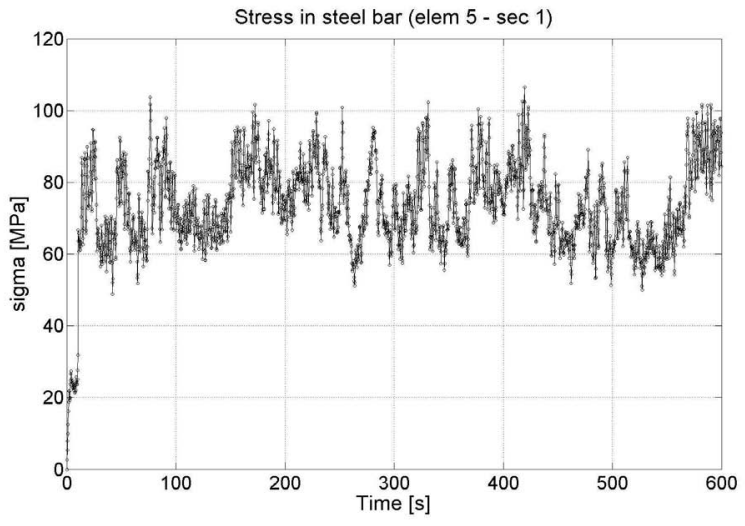

FIGURE 10: Stresses in a steel bar in a damage section at the level of node 5 (non linear structural analysis)

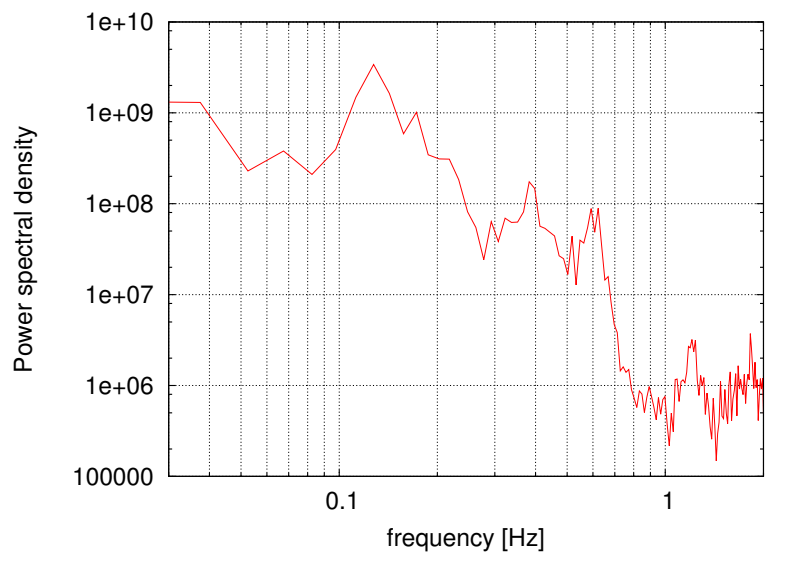

FIGURE 11: Power spectral density on the moment at the substructure base (non linear structural analysis)

moment response of the substructure. At $11.4 \mathrm{~m} / \mathrm{s}$, the rotational speed of the turbine is $12 \mathrm{rpm}$. The 1P turbine excitation frequency is thus $0.2 \mathrm{~Hz}$, and the 3P frequency is $0.6 \mathrm{~Hz}$ (1p equals the rotational frequency, and $3 p$ equals 3 times the rotational frequency). The $3 \mathrm{P}$ frequency is clearly observable on the graph. It is also interesting to note a peak around $0.4 \mathrm{~Hz}$, probably corresponding to the first natural frequency of the turbine tower. This shows that turbine loads are properly transmitted from the turbine to the substructure base.

Damage: Damage due to traction is only observed at the levels of nodes 5 and 6 (the rest of the structure remains in the linear regime), see Figure 12. No damage due to compression is found. One half of the section is damaged as the loading is important only in one direction (not a "true" symmetric load with significant maximum values at both directions).

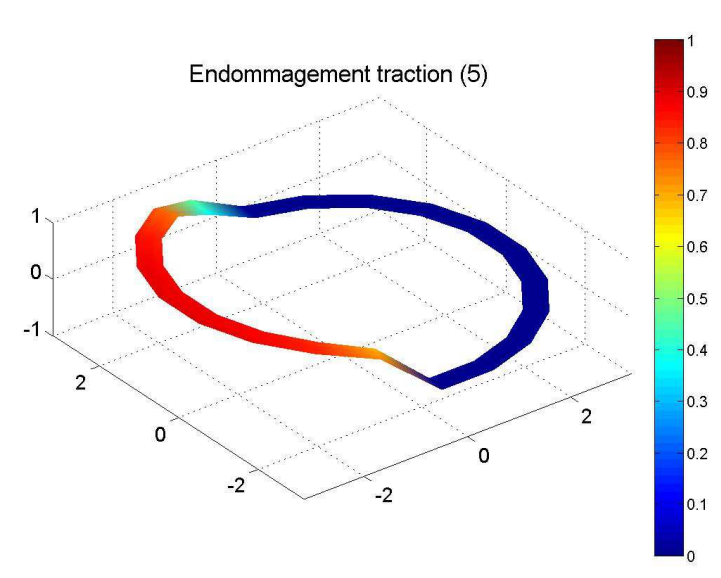

FIGURE 12: Damage due to traction in a section at the level of node 5 (non linear structural analysis)

\section{Effects of soil-structure interaction}

To assess the ability of the integrated numerical strategy to reproduce the effects of soil structure interaction, we compared hereafter the numerical results of the GFB considering or not the macro-element. For both calculations, the nonlinear constitutive laws for concrete and steel are used.

Table 5 shows some statistics of the two simulations. It is found that the horizontal top displacements of the GBF top are significantly increased, in terms of mean and maximum displacements. The results are however similar in terms of moment at the foundation base and stresses in the steel bars. As in [3], the GBF on a B type soil seems to behave more as a fixed structure with the development of plastic hinges in the substructure. Results could be significant different if a less rigid type soil (C) was considered. Results presented here have to be confirmed with macro-element parameters calculated for a marine soil.

\section{CONCLUSION AND FUTURE WORK}

This paper shows the interest of an integrated modelling strategy combining multifiber finite element beams with nonlinear constitutive laws, nonlinear soil structure interaction (macroelement) and nonlinear wave modelling for the structural dynamic modelling of concrete gravity base foundations. The model has been able to efficiently simulate the behaviour of a GBF foundation under nonlinear irregular wave forcing and loads transmitted by the turbine. The model reproduces complex nonlinear phenomena such as decrease in the structural stiffness due to damage, permanent strains, and the amplification of the horizontal top displacement due to soil structure interaction.

Even if each numerical tool used in this study has already been validated independently, it will now be necessary to vali- 


\begin{tabular}{llccc}
\hline & & NL & NL +SSI & Diff. [\%] \\
\hline Top displacements [m] & mean & $3.93 \mathrm{E}-02$ & $4.24 \mathrm{E}-02$ & $8 \%$ \\
& max & $5.54 \mathrm{E}-02$ & $6.04 \mathrm{E}-02$ & $9 \%$ \\
& std & $5.90 \mathrm{E}-03$ & $6.40 \mathrm{E}-03$ & $8 \%$ \\
\hline Overturning moment at node 1 [kN.m] & mean & $7.56 \mathrm{E}+04$ & $7.56 \mathrm{E}+04$ & $0 \%$ \\
& max & $1.30 \mathrm{E}+05$ & $1.30 \mathrm{E}+05$ & $0 \%$ \\
& std & $1.61 \mathrm{E}+04$ & $1.61 \mathrm{E}+04$ & $0 \%$ \\
\hline Stresses in a steel bar (elem 5) [MPa] & mean & $7.33 \mathrm{E}+01$ & $7.33 \mathrm{E}+01$ & $0 \%$ \\
& max & $1.06 \mathrm{E}+02$ & $1.06 \mathrm{E}+02$ & $0 \%$ \\
& std & $1.27 \mathrm{E}+01$ & $1.27 \mathrm{E}+01$ & $0 \%$ \\
\hline
\end{tabular}

TABLE 5: Comparison of statistical results considering or not soil structure interaction (NL: NonLinear structural analysis and cantilevered foundation ; NL+SSI: Non Linear structural analysis and macro-element for Soil Structure Interaction)

date the combination of these tools for offshore wind turbine applications. Results have to be validated using more advanced and time consuming numerical models, including 3D FEM models for soil-structure interaction and CFD models for fluid-structure interactions. Comparison with experimental data would also be of great interest. Once validated, the model will be applied on a variety of design load cases including fatigue limit states and extreme limit states. This work will now continue in the following ways :

- A more detailed analysis of the structural dynamics of the GBF will be performed including comparison of multiple design load cases in order to identify the most severe ones for the concrete structure. The influence of wind loads and wave loads on the dynamics of the structure will be quantified and design guidelines will be provided.

- A more refined mesh will be used for the nonlinear structural analysis in order to identify and to localize with more precision the existence and the position of the plastic hinges

- Parametric studies will be performed to identify the influence of parameters such as wind speed, wave conditions and soil stiffness. Results will be compared to reference results on other type of substructure (such as the OC3 project [11]), to assess the need of a coupling between the structure model and the wind turbine model.

- The effect of soil-structure interaction will be assessed through comparison considering different types of soil.

\section{ACKNOWLEDGMENT}

The authors would like to acknowledge Kévin GUIOT from INNOSEA for his help in GBF geometry definition, and Rocio ISORNA from INNOSEA for her help in the structural analysis.

\section{REFERENCES}

[1] Kotronis, P., and Mazars, J., 2005. "Simplified modelling strategies to simulate the dynamic behaviour of r/c walls". Journal of Earthquake Engineering, 9:2, pp. 285-306.

[2] Mazars, J., Kotronis, P., Ragueneau, F., and Casaux, G., 2006. "Using multifiber beams to account for shear and torsion. applications to concrete structural elements.". Computer Methods in Applied Mechanics and Engineering, 195(52), pp. 7264-7281.

[3] Grange, S., Botrugno, L., Kotronis, P., and Tamagnini, C., 2011. "The effects of soilstructure interaction on a reinforced concrete viaduct". Eathquake Engineering and Strctural Dynamics, 40, pp. 93-105.

[4] La Borderie, C., 1991. "Phénomnes unilatéraux dans un matériau endommageable : modélisation et application à l'analyse des structures en béton". PhD thesis, Université Paris 6.

[5] Menegotto, M., and Pinto, P., 1973. "Method of analysis of cyclically loaded reinforced concrete plane frames including changes in geometry and non-elastic behaviour of elements under combined normal force and bending". In IABSE Symposium on Resistance and Ultimate Deformability of Structures Acted on by Well-defined Repeated Loads, Final Report, Lisbon.

[6] Grange, S., Kotronis, P., and Mazars, J., 2008. "A macroelement for a circular foundation to simulate $3 \mathrm{~d}$ soilstructure interaction". Iinternational Journal for Numerical and Analytical Methods in Geomechanics, 32, p. 12051227.

[7] Piere, K., Nonneman, H., and Bosschem, E., 2009. "Gravity base foundations for the thornton bank offshore wind farm". Terra et Aqua, 115, pp. 19-29.

[8] Jonkman, J., Butterfield, S., Musial, W., and Scott, G., 2009. Definition of a 5-MW Reference Wind Turbine for Offshore System Development. Tech. Rep. NREL/TP-50039060, National Renewable Energy Laboratory.

[9] Jonkman, J., 2009. Definition of a floating system for phase IV of OC3. Tech. rep., National Renewable Energy Laboratory.

[10] Iec 61400-1, international standard, wind turbines part 1: Design requirements.

[11] Jonkman, J., and al., 2010. "Offshore code comparison collaboration within iea wind task 23: Phase iv results regarding floating wind turbine modeling". European Wind Energy Conference.

[12] Seidel, M., Von Mutius, M., Rix, P., and Steudel, D., 2005. "Integrated analysis of wind and wave loading for complex support structures of offshore wind turbines". In Conference Proceedings Offshore Wind 2005. Copenhagen 2005.

[13] Kaufer, D., Cosack, N., Bker, C., Seidel, M., and Khn, M., 2009. "Integrated analysis of the dynamics of offshore wind turbines with arbitrary support structures". In Conference Proceedings European Wind Energy Conference, 
Marseille, 2009.

[14] Henderson, A., Zaaijer, M., and Camp, T., 2003. "Hydrodynamic loading on offshore wind turbines". In Offshore Wind Energy in the Mediterranean and Other European Seas Conference [OWEMES].

[15] Henderson, A., and Zaaijer, M., 2008. "Hydrodynamic loading on offshore wind turbine support structures". Engineering integrity, 25, pp. 24-31.

[16] West, B., Brueckner, K., Janda, R., Milder, D., and Milton, R., 1987. "A new numerical method for surface hydrodynamics". Journal of Geophysical Research, 92(C11), pp. 11803-11.

[17] Dommermuth, D., and Yue, D., 1987. "A high-order spectral method for the study of nonlinear gravity waves". Journal of Fluid Mechanics, 184(1), pp. 267-288.

[18] Ducrozet, G., Bonnefoy, F., Touzé, D. L., and Ferrant, P., 2012. "A modified high-order spectral method for wavemaker modeling in a numerical wave tank". European Journal of Mechanics - B/Fluids, 34(0), pp. $19-34$.

[19] Ducrozet, G., Bonnefoy, F., Le Touzé, D., and Ferrant, P., 2007. "3-d hos simulations of extreme waves in open seas". Natural Hazards and Earth System Science, 7(1), pp. 109122.

[20] Gilloteaux, J., Babarit, A., Ducrozet, G., Durand, M., and Clément, A., 2007. "A non-linear potential model to predict large-amplitude-motions: Application to the searev wave energy converter". International Conference on Ocean, Offshore and Arctic Engineering.

[21] Delhommeau, G., 1993. "Seakeeping codes aquadyn and aquaplus". In 19th WEGEMT School Numerical Simulation of Hydrodynamics: Ships and Offshore Structures.

[22] FC Filippou and M constantinides, 2004. FEDEASLab getting started guideand simulations examples. Departement of Civil and Environmental Engineering, UC Berkeley.

[23] Grange, S., Kotronis, P., and Mazars, J., 2008. "A macro-element for a shallow foundation to simulate soilstructure interaction considering uplift". Comptes Rendus Mécanique, 336(11), pp. 856-862.

[24] Grange, S., Kotronis, P., and Mazars, J., 2009. "A macroelement to simulate $3 \mathrm{~d}$ soil-structure interaction considering plasticity and uplift". International Journal of Solids and Structures, 46(20), pp. 3651-3663.

[25] Grange, S., Kotronis, P., and Mazars, J., 2009. "A macroelement to simulate dynamic soil-structure interaction". Engineering Structures, 31(12), pp. 3034-3046.

[26] J. Jonkman and M. Buhl, 2005. FAST User Guide. National Renewable Energy Laboratory. 